\title{
In search of new paradigms to interpret and design the contemporary city
}

\author{
R. Cocci Grifoni, R. D’Onofrio \& M. Sargolini \\ SAD (Scuola di Architettura e Design "E.Vittoria”),UNICAM, Italy
}

\begin{abstract}
In recent decades, the idea has prevailed that sustainable development is not translatable into specific economic and urban transformation objectives alternative to the traditional ones, but should be understood as a long-term process, a set of measures taken to mitigate adverse effects without calling into question the trends underlying cities' growth. This approach has produced a series of experimental results, only a few cases of which show mature and practical applications to improve the environmental quality and social development of our cities.

Today a cultural revolution is needed. The confirmed theoretical complexity of sustainable development and the growing availability of metrics for sustainability and people's well-being call for a cross-cutting approach to urban planning. It must be able to reinterpret the relationships between different components of the city - physical, environmental, morphological, historical and socio-economic - in a transdisciplinary manner, with the aim of ensuring the overall sustainability of the changes.

The proposed approach (applied in the town of Pineto, Italy), views the city as an "urban organism" structured in multiple intertwined layers, i.e., an evolutionary system whose meaning is higher than the sum of its parts, and which requires dynamic analysis and integral solutions to ensure sustainability.

In this view, a comprehensive dynamic analysis and the contribution of multiple integrated disciplinary skills (such as thermodynamics, ecology, statistical mechanics, technological sciences, economics, sociology, urban planning and architectural composition) are essential for identifying rules to ensure the balance and sustainability of change regarding the maintenance and
\end{abstract}


increasing integrity of the natural environment, landscape, and the proper operation of technological networks and territorial energy efficiency to improve the quality of life of the citizens.

Keywords: transdisciplinary approach, urban planning, environmental compatibility, urban parameterization, outdoor thermal comfort, thermo fluid dynamic analysis.

\section{Introduction}

The concept of urban sustainability, in all its ambiguity, is at the heart of reflections on the contemporary city, and generates questions about the concept of "city" and about urban culture paradigms that have been established with the Modern Movement. Among the principal causes of the current crisis are the malfunctioning of urban organisms and their metabolism, settlement dispersion, wasteful building, traffic congestion, the continual occupation of new spaces, and the destruction of the natural heritage and agricultural territory [1]. Today, however, it seems evident that one of the reasons for the crisis should be linked to the concept of the urban organism itself and with its operation and control methods.

This interpretation finds difficulty making in-roads; in fact, in recent decades the idea has prevailed that sustainable development is not translatable into precise economic and urban transformation objectives alternative to traditional ones, but rather should be exclusively understood as a long process, as the combination of interventions aimed at mitigating precise negative effects without reconsidering the trends underlying city growth.

In ordinary practice, urban and territorial planning has reduced the complexity of urban systems, considering them to be substantially stable with the delusion that transformations were preventable and controllable, and thinking about sustainability not as a process and a constantly changing course, but as a final stable state. At times, the temptation to intervene on a limited small scale, and, in many cases, the search for possible solutions to contrast the effects of climate change has been delegated to other disciplines, favouring sectorial-type responses that have rather limited efficiency.

The modest success of politics attempted up to now (mainly regarding the existing city), the global economic crisis and above all the energy crisis and environmental catastrophe call for a radical rethinking of the contents and means by which to trigger real environmental, social, and economic sustainability. The uncertain success of international politics, emerging after the failure of the recent climate conference in Durban, obliges those dealing with city projects to examine new principles of responsibility implicit in a broader view of the city and to search for new configurations of the disperse city (or the exploded city, as some authors tend to refer to it).

In this new scenario, urban planning is called to assume its proper responsibility, interpreting the relationships between the different physical, environmental, morphological, historical and socio-economic components of the city with a transdisciplinary approach. Such an approach necessarily requires 
recourse to an adaptive and incremental planning process that introduces the time variable into the implementation of politics, actions and precise outcome indicators by means of monitoring and eventually correcting the choices made.

\section{Objectives of urban sustainability and a transdisciplinary approach}

Cities can and should become places in which to experiment with new, more sustainable ways of living and working, new social relationships, smarter ways of using one's time and a better quality of life not necessarily associated with an increase in material consumption.

If sustainable urban development is, as numerous studies and international reports suggest, firstly a process enriched by collective learning, the ability to settle conflicts and a capacity for strategic design, this is primarily the result of synergistic integration and of co-evolution between the large subsystems (economic, social, and physical-environmental) of which the city is composed.

To obtain a substantial evolutionary equilibrium between these subsystems, it is necessary to promote politics of intervention that approaches the theme of urban sustainability from three principal directions: technology (most importantly energy and transport), the environment and urban shape and the habitus (characteristics of individual demeanour).

It is also necessary to promote politics and actions that not only allow the urban organism to adapt to climate changes, but which are also capable of constructing new social, economic and environmental responses to allow the city to withstand environmental and historical stress for a long time.

The promotion of this balance, which should therefore be aimed at increasing the resilience of the city, is among the new tasks of urban discipline, which, with such a goal, is called to act first and foremost on organizational and managerial models of the city [2].

Current urban complexity requires the selection of a transdisciplinary approach that can propose new interpretive modes, such as : the analysis of the cycles and environmental networks in relation to the city's infrastructure, energy and settlement networks; the limits of urban growth in relation to carrying capacity criteria applied to the urban environment; environmental comfort in relation to the quality of life in the urban environment; the thermodynamic "open city" system in a non-equilibrium state, etc.

If urban planning would assume the task of investigating problems of the contemporary city in all their complexity with the aim of identifying the sustainability objectives to form the basis of politics, programs, actions and projects, it should face the need to "measure" sustainability. To do this, it is necessary to arrange technical systems based on parameters that are able to describe and temporally measure the state of the urban environment in its different components and its level of sustainability [3]. 


\section{Evaluating urban sustainability}

In the disciplinary debate, one often complains about a lack of instruments suitable to ensure that from good sustainable ideas one can move on to coherent, efficient, effective actions. To evaluate the sustainability of changes, one references sustainability indicators, instruments capable of representing a phenomenon and contributing to the building of knowledge [4].

However, the choice of indicators is not often simple. Although they have been the objects of elaboration on behalf of different international organizations for some time, they mostly deal with single aspects, such as mobility, construction, the ecological requalification of green spaces and the containment of land use [5].

Therefore, they are often inadequate to appreciate the complexity of settlement systems and wind up being inefficient in proposing elements of constant cyclic support with respect to strategic-structural and operational instruments in urban planning.

Some examples may be useful in clarifying this problem.

Increasing urban densification can lead to better energetic efficiency of the developed area, reducing movement and its related consumption. However, beyond a certain extension, the same operation can also generate many negative effects due to traffic congestion and the high concentration of pollution, in addition to the impermeabilization of extensive areas of land, resulting in a greater dispersion of pollutants; none of this is implied by a low population density. In addition, excessive densification can lead to negative repercussions on ecological cycles and on the environmental comfort of the city.

Evidently each sustainability objective that comes up in a planning process should be defined, considering coherence and compatibility with other decisions and with other aspects and parameters of sustainability, since it is often through their interaction that effective sustainability success can be obtained.

With such an aim, it seems particularly useful to test "urban parameterisation" models that can be placed next to various operational planning instruments via: a meteorological-climate characterization of the city and its various parts; the analysis of geometrical factors and the evaluation of soil permeability and land use. Such experimentation can, for example, contribute to resolving the controversy between compact and diffuse cities in relation to the settlements' environmental sustainability from the moment that the "compact city" model reveals a series of contradictions in terms of better energy efficiency or fewer trade-offs in natural areas, when they are put to the test by more closely analysing the relationship between urban form and natural processes.

\section{Parameterization of the urban area}

Cities have always been the places with the highest energy demand; and yet, the focus on both the necessary analysis and interventions, is still insufficient. Moreover, urbanization accounts for a decisive change of climate, with meaningful effects on the meteorological variables (sun radiation, temperature, 
relative humidity, rainfall, wind) that influence the outdoor environmental comfort. A thorough analysis of and a quantitative approach to the study of urban effects on climate, allow to gather the knowledge and develop those tools and methods necessary for a correct assessment of the impact on urban climate of the actions provided for by the instruments used in urban planning.

The urban heat island phenomenon is closely related to the cities energy consumption and to the conditions of environmental comfort in open spaces [6].

Any inhabited place, small as it is, has its own urban heat island. Usually, the intensity of the heat islands grows with increasing population.

Landsberg [7] has discovered that the UHI mean value can be expressed either on the basis of the city diameter " $\mathrm{d}$ " $(\mathrm{km})$, or on the basis of the number of inhabitants "Na" (strictly correlated to the anthropogenic sources), according to the following empiric relations:

$$
\Delta t_{(u-r)}=0.10 \cdot d \quad\left[{ }^{\circ} \mathrm{C}\right] \quad O T
$$

and

$$
\Delta t_{(u-r)}=0.870 \cdot \ln \left(N_{a}\right)-4.012 \quad\left[{ }^{\circ} \mathrm{C}\right]
$$

Likewise, Oke [8] introduced the contribution of the wind speed (U) measured at $10 \mathrm{~m}$ off the ground, according to their respective relations:

$$
\Delta t_{(u-r)}=\frac{P^{0.25}}{(4 U)^{0.5}}
$$

Moreover, Oke, correlated the intensity of the thermic gradient $\Delta \mathrm{t}(\mathrm{u}-\mathrm{r})$ to the Sky View Factor, or height/width H/W (urban geometry factor) relation:

$$
\Delta t_{(u-r)}=7.45+3.97 \cdot \ln \left(\frac{H}{W}\right)
$$

The heat island phenomenon decreases in case of a very clouded sky or very strong winds: these two factors determine the "weight", the incidence of local scale climate on a synoptic scale wind. In fact, the presence of clouds implies a meaningful reduction of the quantity of direct solar radiation incident to the ground, resulting in a reduction of all the correlated phenomena, such as solar energy absorption, high store and re-irradiation of thermic energy, etc.

Strong winds, with high speed air flows, imply a quick dispersion of the heat released into the air by the materials that make up the urban set up, as well as a faster dissipation of the polluting agents dispersed in the atmosphere (these agents are the cause of an increase of infrared radiations coming from the sky).

In order to assess more exactly the real comfort/environment behaviour of urban area and human settlements, it is necessary to consider the phenomenon of the urban heat island.

Two more issues that contribute to the change of the hydro-geologic budget in urban areas in comparison with the surrounding rural areas, are the decrease of the evaporation/transpiration and of the underground downflow, and the equivalent increase of the surface downflow. 
The evaluation of these parameters for the case study can individuate a first step for the quantitative analysis approach in the sustainable urban planning.

\subsection{The environmental compensation}

It is clear that actions of anthropic modification of the grounds require actions of environmental compensation aiming at rebalancing the terms of hydrologic and energetic budgets.

In particular, it will be necessary to cut down the heat flow stored in the urban structure, increase the vegetation and the amount of evaporable water (i.e. to reduce latent heat flow), reduce the anthropogenic heat flow, reduce the net radiation and ultimately reduce the water soaking up from the underground layers

An efficient algorithm (namely R.I.E. index [9]) has been used to evaluate the environmental compensation in the quarter Villa Fumosa of Pineto City. It is introduced by the City of Bolzano in northern Italy. It is an index that is intended to be a numerical index of the environmental quality. It is applied to a building lot to assess its environmental quality considering soil permeability and green extent.

It expresses the ratio between the elements modifying the land use and the management of storm water:

$$
\text { R.I.E. }=\frac{\sum_{i=1}^{n} S v_{i} \cdot \frac{1}{\psi_{i}}+(S e)}{\sum_{i=1}^{n} S v_{i}+\sum_{j=1}^{m} S i_{j} \cdot \psi_{i}}
$$

where:

Svi: i-th pervious surface, green impermeable or green sealed surface;

Sij: $\mathrm{j}$-th pervious surface, not green impermeable or not green sealed surface;

$\Psi \mathrm{i}$ : run-off coefficient

Se : equivalent surfaces with trees.

The modification of the land use could be positive (improved water collection) or negative (smaller water run-off). The higher is the R.I.E. index, the better is the management of the land with regard to the quantity of infiltrated storm water and to the benefits for the micro-climate and the environment.

\section{First application: the Villa Fumosa quarter in the new PRG (Piano Regolatore Generale) of Pineto (Italy)}

\subsection{Description of the context and characteristics of the study area}

For years, the School of Architecture and Design (SAD) at the University of Camerino, Ascoli Piceno, has undertaken research on "Città Adriatica" that, for 
the last few years, has pertained to ongoing consulting for the spin-off "Terre S.r.l." that deals with drafting the new PRG (Local Plan) of the City of Pineto, a town of about 14,000 people in the province of Teramo (in the middle of Italy).

This coastal city, whose origin is linked to the opening of the Adriatic railroad in 1863, has experienced significant growth since the 1950s, with an increase in population (rising from 5900 inhabitants in 1930, to about 6800 in 1961, to around 14,000 inhabitants in 2005) due to the development of manufacturing and tourist activities.

Since the post-war era, the imposing economic and social transformations that have occurred, along with the development of tourism, productive areas and new residential areas, have not always been in harmony or balance with the demands of soil defence and landscape protection, but rather have often contributed to triggering a process of land use, hydro-geological instability and the impoverishment of nature and the landscape, which is becoming ever more evident.

In particular, the increase of impermeable surfaces, the transformation of agricultural practices directed towards mechanized cultivation of the land, the consequent disappearance of drainage, the abandonment of maintaining the private hydraulic network and the realization of productive and residential areas in places at risk of landslides and flooding now represent the factors reducing the hydraulic security of agricultural and settled areas. The result is a territory with progressively decreasing hydraulic security, in which mitigation interventions and ecological rebalancing are absent, above all in areas characterized by the presence of major manufacturing and urban settlements.

The new PRG being drafted along with the DPP (Preliminary Planning Document) adopts the theory that the process of sustainable planning imposes a cultural revolution that should know how to reinterpret relationships between the different physical and environmental, morphological, historical and socioeconomic components of Pineto with a transdisciplinary approach aimed on the whole at ensuring the sustainability of the transformations.

The Plan proposes contributions to ensure the environmental, technological and morphological compatibility of settlements and activities, forecasting specific systematic planning actions and strategic projects for the locality in the DPP.

Parallel to drafting the DPP, experimentation of an "urban parameterisation" model is being developed, to be applied in an area of recent construction located along the Adriatic state highway, in order to verify the environmental and morphological compatibility of the proposals contained in the DPP. The experiment is proceeding by contrasting the stability proposal of the DPP with that envisaged by the prevailing PRG, today only partially enacted, by means of a meteorological-climate characterization of the Villa Fumosa quarter through the analysis of its geometrical factors and the evaluation of the soil permeability and land use.

The quarter under study, of flat geography, has an elongated rectangular area of $430,000 \mathrm{~m}^{2}$ and is limited on the east by the Adriatic Sea and on the west by the coastal hills Fig. 1). The SS16 and the Adriatic railroad separate the touristic 
zone (a low-density tourist town is present with an area of about $90,000 \mathrm{~m}^{2}$ ) from a low-density residential zone (max. 3 floors), inside of which lies an agricultural zone that is still active. This area, about $13,000 \mathrm{~m}^{2}$, is half occupied by a factory. The residential zone is not fully established; part of the green areas, public fixtures and parking are missing. The PRG in force provides a maximum developed area of $41,000 \mathrm{~m}^{2}$ for the residential zone, divided between residential areas and tourist accommodation.

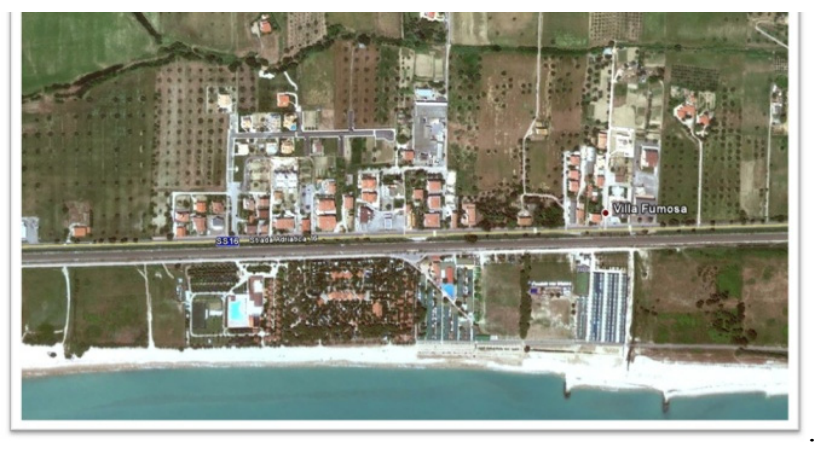

Figure 1: Villa Fumosa quarter (ante operam).

The DPP, while confirming the tourist zone and residential settlement, foresees the demolition of the artisanal factory and the transformation of the area into an urban centre, adorned with green areas and permeable spaces, residences and services. The DPP also foresees the realization of green wedges (an urban park and an agricultural area) at the northern edge and south of the experimentation area, and a linear park toward the north along the border with the coastal hills, crossed by a cycling path with connection to central Pineto. Other projected interventions deal with securing the area from the risk of landslides and floods, through the realization/maintenance of artificial drainage canals.

\subsection{Urban parametrization}

The aim of PRG, already underway, is therefore to furnish indications, suggestions and rules to direct the preliminary planning choices contained in the DPP toward the goal of environmental sustainability and the living comfort of the area under examination. This takes place by suggesting corrections: for the best definition of the form and use of open spaces, with particular attention to green areas, permeable areas and the sizing of streets; for the definition of the best building density; and for the correct placement of buildings and functional uses.

A first evaluation of urban parametrization (table 1) has been applied to the quarter of Villanova where R.I.E. index and UHI mean value (as well as in the equation 5), have been evaluated for the "ante operam" scenario (the existing situation, Fig. 1) and "post operam" scenarios (the planned scenario, Fig. 2). 


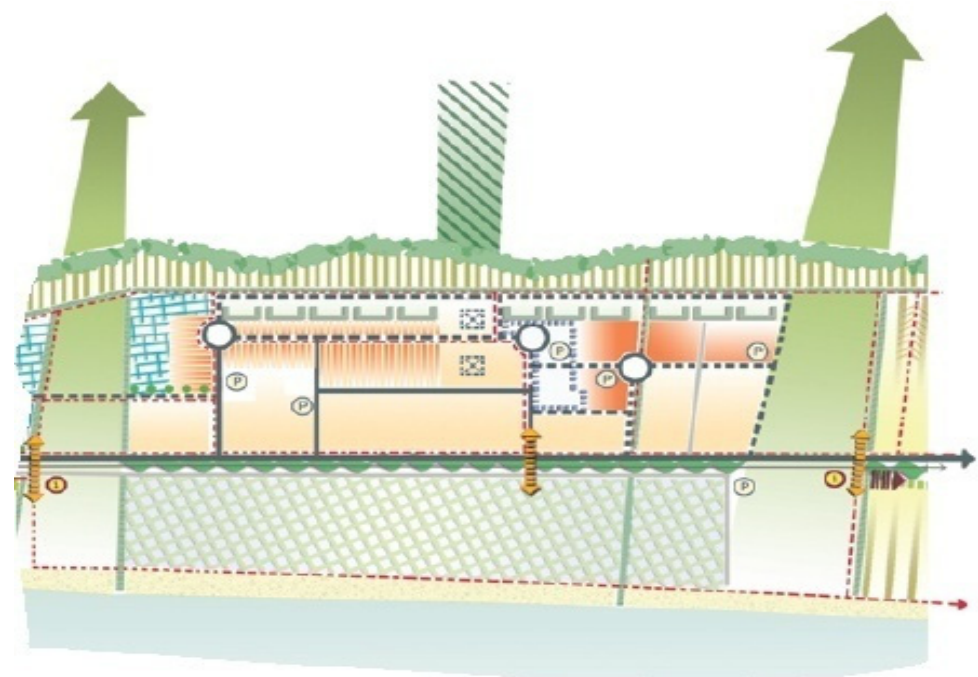

Figure 2: $\quad$ Villa Fumosa quarter (post operam).

Table 1 show a comparison between values calculated for ante and post operam scenarios and the analysis of the obtained results can quantify the magnitude of the urban canyon layer heat island effect UHI, population density and green cover fraction.

The post operam configuration seeks to optimize building and street proportions, open space, air movement, pervious materials and green infrastructure relative to thermal comfort and Urban Heat Island mitigation.

Table 1: $\quad$ Urban parameters selected.

\begin{tabular}{|cc|cc|}
\hline \multicolumn{2}{|c|}{ Ante operam } & \multicolumn{2}{c|}{ Post operam } \\
\hline$\Delta t_{(u-r)=3,800}$ & $\Delta t_{(u-r)=2,90}$ & eq. (5) \\
\hline R.I.E. $=3,74$ & eq. (6) & R.I.E. $=5,11$ & eq. (6) \\
\hline
\end{tabular}

\subsection{Envi-met simulation}

ENVI-met [10] is an efficient tool which analyzes micro-scale thermal interactions in urban environments. It is a user friendly tool that aims at reproducing the major processes in the atmosphere that affect the microclimate on a well-founded physical basis (i.e. the fundamental laws of fluid dynamics and thermodynamics). It is a three-dimensional non-hydrostatic model for the simulation of surface-plant-air interactions inside urban environments. It is designed for microscale simulations with a typical horizontal resolution from 0.5 to $10 \mathrm{~m}$. This resolution allows a fine reading of the microclimatic changes, especially sensible to urban geometry and relevant for comfort issues and analysis of small-scale interactions between individual buildings, surfaces and 
plants. The vegetation is handled not only as a porous obstacle to wind and solar radiation, but also including the physiological processes of evapotranspiration and photosynthesis. Various types of vegetation with specific properties can be used. The soil is also considered as a volume composed of several layers and the ground can be of various types. The evaluation of thermal index Predicted Mean Vote (Pmv) has been assessed for the Villanova area. The PMV index indicates comfort when lying around zero $(-0.5$ to +0.5$)$. The deviation from zero was referred to as thermal stress and varies on a seven-point scale from -3 (cold stress) to +3 (heat stress).

The simulation is started at 6:00 LST when most atmospheric processes are slow and a very low wind speed value has been considered $(1.8 \mathrm{~m} / \mathrm{s})$ accordingly to meteorological data. Simulations are run during daytime hours, because daylight hours represent the time of the day with a regular frequentation use of outdoor spaces. Calculations were performed during the summer period and in two different scenarios, ante operam configuration as well as post operam configuration, have been considered.

Fig. 3 represents the ENVI-met output (Predicted Mean Vote index) for the first simulated scenario (ante operam configuration). From these colour maps it can be observed the high values for PMV index on almost all points, resulting in quite poor thermal comfort conditions (hot).

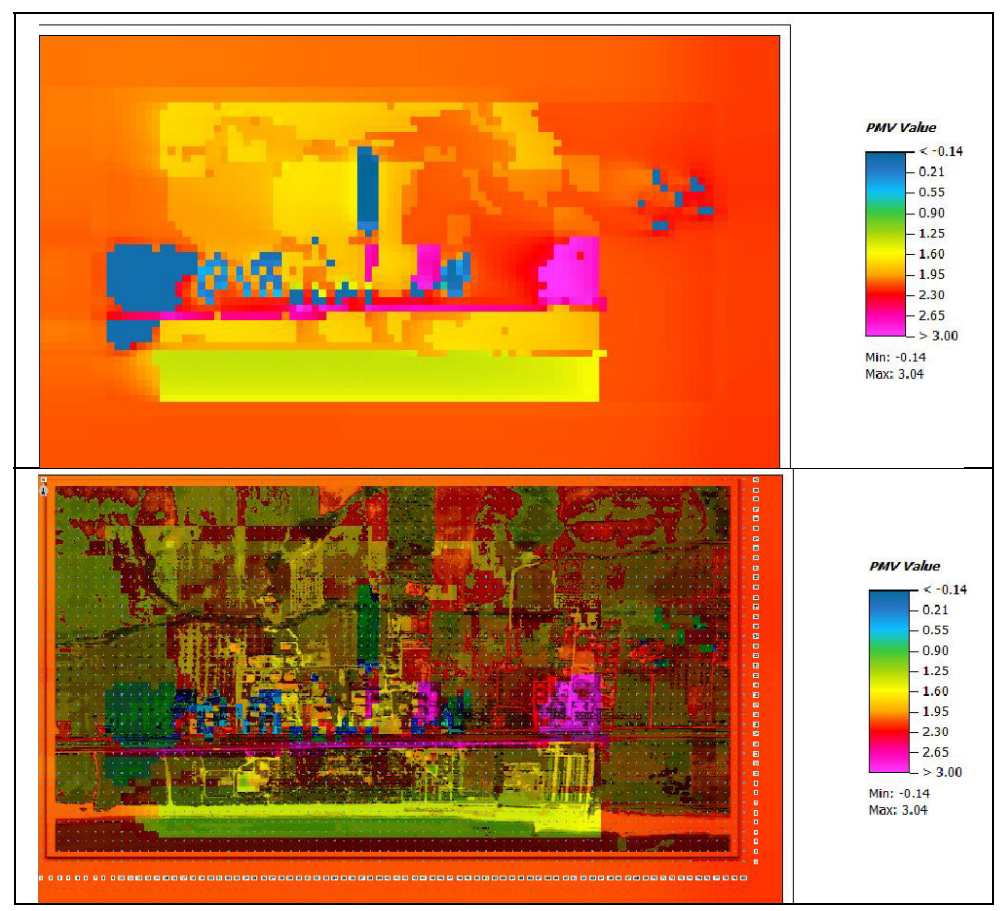

Figure 3: Map of PMV index (ENVI-met simulation) for ante operam scenario. (See online for colour version.) 
For the second simulated scenario (post operam configuration) colour map (Fig. 4) shows lower values for PMV index in more points (namely green belt and green corridors in the blue areas), resulting in a better comfort condition.

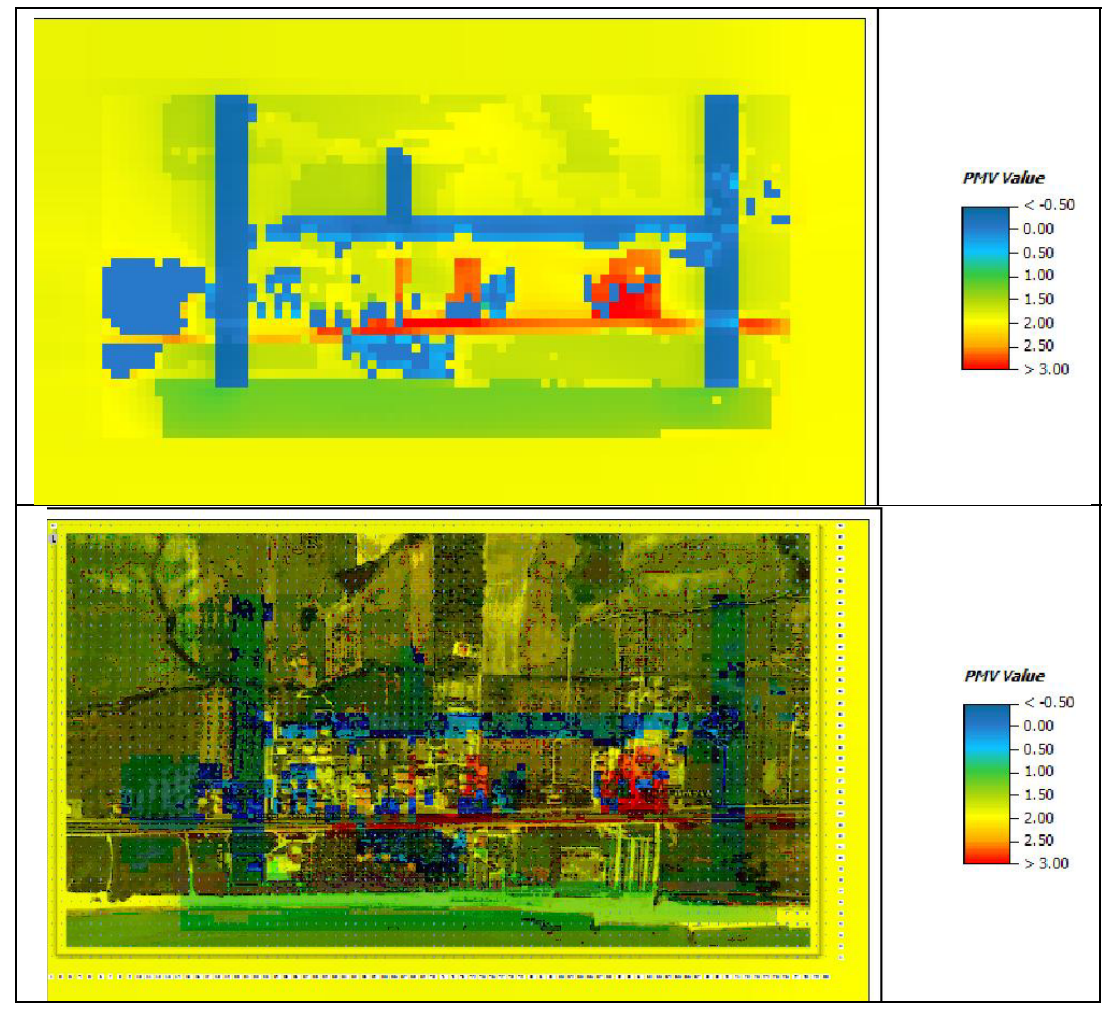

Figure 4: Map of PMV index (ENVI-met simulation) for post operam scenario. (See online for colour version.)

\section{Conclusions}

The aim of this paper was to provide theoretical, methodological and operative tools for exploring the "urban organism", taking into account its climate, morphology, environmental dimension, quality and efficiency of housing and services and sustainable mobility. In this way, the transdisciplinary approach ensures the sustainability of the urban transformations and shows how green design and sustainable planning can achieve urban comfort and energy saving. A first case study has been considered focusing on green infrastructure in urban areas that can ameliorate the warming effects of climate change and the urban heat island. The cooling effect of greenbelt and green corridors are very important results to improve thermal comfort and quality of life. These results 
can represent benefit for the local government to make some measurements to alleviate thermal environmental problems in the city and to reach a more sustainable development at the local level.

\section{References}

[1] Beatley T., Newman P., Boyer H., Resilient Cities: Responding to Peak Oil and Climate Change, Island Press, Washington 2009.

[2] Beaupuy J. M., Bâtir des villes durables, Yves Michel, 2008.

[3] Bosio M., Frate M. (a cura di), Strategie per il progetto della città sostenibile, IUAV Venezia, Marsilio, Venezia, 2010.

[4] Owens S., Cowell R., Land and limits: interpreting sustainability in the planning process, Routledge, London, New York, 2011.

[5] Rogora A., Dessì V., Il comfort ambientale negli spazi aperti, Edicom edizioni, Monfalcone, 2005.

[6] Nikolopoulou, M., S. Lykoudis, Thermal comfort in outdoor urban spaces: Analysis across different European countries. Building and Environment 41, 1455-1470, 2006.

[7] Landsberg H. E., City Climate, General Climatology, World Survey of Climatology, Vol. 3, Ed. Elsevier, Amsterdam, 1981.

[8] Oke T. R., The surface energy budgets of urban areas, Modelling the urban layer, Ed. AMS, Boston, 1981.

[9] U.T.B.A. Bolzano,Manuale d'uso del foglio di lavoro Excel per calcolo del R.I.E., Ed. U. Giardineria Comunale, Bolzano, 2007.

[10] Bruse, M. and Fleer H., Simulating surface-plant air interactions inside urban environments with a three dimensional numerical model, Environ. Modell. Softw. 13, 373-384, 1998. 